\title{
IL-10 expression is regulated by HPV E2 protein in cervical cancer cells
}

\author{
V.H. BERMÚDEZ-MORALES ${ }^{1}$, O. PERALTA-ZARAGOZA ${ }^{1}$, \\ J.M. ALCOCER-GONZÁLEZ ${ }^{2}$, J. MORENO ${ }^{1}$ and V. MADRID-MARINA ${ }^{1}$ \\ ${ }^{1}$ Division of Chronic Infections and Cancer, CISEI, National Institute of Public Heath, Morelos 62100; \\ ${ }^{2}$ School of Biological Sciences, Autonomous University of Nuevo Leon, Nuevo Leon 66450, Mexico
}

Received September 20, 2010; Accepted January 11, 2011

DOI: $10.3892 / \mathrm{mmr} .2011 .429$

\begin{abstract}
It has been found that certain cytokines (IL-4, IL-10 and TGF- $\beta 1$ ) are highly expressed locally in biopsies from patients with premalignant lesions and cervical cancer, and may induce a local immune-suppression state. In particular, IL-10 is highly expressed in tumor cells and its expression is directly proportional to the development of HPV-positive cervical cancer, suggesting an important role of HPV proteins in the expression of IL-10. In fact, we demonstrated that E6 and E7 HPV proteins regulate TGF- $\beta 1$ gene expression in cervical cancer cells. Here, we found by band shifting analysis that the HPV E2 protein binds to the regulatory region of the human IL-10 gene (-2054 nt) and induces high promoter activity in epithelial cells. Additionally, cervical cancer cells transfected to express the HPV E2 protein induce elevated levels of IL-10 mRNA in human papillomavirus-infected cells. The elevated expression of IL-10 may allow for virus persistency, the transformation of cervical epithelial cells, and consequently cancer development.
\end{abstract}

\section{Introduction}

Cervical cancer is the second most common cause of cancerrelated death in women worldwide. The main etiological factor that plays a seemingly crucial role in the development of this cancer is infection with oncogenic human papillomavirus (HPV) $(1,2)$. Host factors are also critical in regulating tumor growth, and cytokines that modulate immunologic control may be of particular importance. In cervical cancer associated with HPV infection, anti-inflamatory and immunosupresive cytokines are expressed in the cervical microenvironment, determining the persistence of HPV and tumor progression by

Correspondence to: Dr Vicente Madrid-Marina, Division of Chronic Infections and Cancer, National Institute of Public Health, Av. Universidad 655, Col. Santa María, Ahuacatitlán Cuernavaca, Morelos 62100, México

E-mail: vmarina@correo.insp.mx

Key words: cervical cancer, E2, human papillomavirus-16, interleukin-10 subverting cellular immune surveillance mechanisms, whether the shift is a secondary effect induced by the tumor cells, or whether it's due to the persistence of the viral infection itself $(3,4)$.

Significantly higher interleukin (IL)-10 levels are expressed in the cervical epithelium of patients with cervical dyspasias compared to the normal cervix $(3,5-9)$. IL-10 expression is directly associated with the degree of cervical lesions (6) and is correlated with the presence of HPV infection $(3,10)$. This suggests that IL-10 is produced by cervical epithelial cells, which have the potential to influence inflammation and cellular immunity in the cervical mucosa, and that this effect may be controlled by HPV proteins promoting tumor cell proliferation and creating a local immunosuppressive state for cancer evolution.

The expression of certain cytokines may be induced by HPV and is produced in transformed cells as a mechanism of escape from the immune response. It has been demonstrated that specific HPV proteins regulate several human heterologous promoters, including HPV-16 E5, E6 and E7 oncoproteins, and transactivate a large variety of viral and cellular gene promoters (11-14), and that E2 protein activates transcription from the viral locus control region (LCR) and interacts with cellular proteins and transcription factors (15). In addition, it has been determined that the HPV-16 E6 and E7 proteins regulate TGF- $\beta 1$ gene expression in human fibroblasts and epithelial cells (16). In particular, our group has demonstrated that the HPV-16 E6 and E7 oncoproteins transactivate the TGF- $\beta 1$ promoter throughout the Sp1 regulatory element (17). This evidence supports the notion that HPV proteins influence the gene expression of immune response, and this scenario represents a relevant immune escape strategy in the HPV-mediated carcinogenesis process.

Regarding the regulatory region of the IL-10 gene, the IL-10 promoter has previously been characterized and the transcriptional activity of reporter genes in various lymphoid cell lines has been demonstrated (18-20). Promoter activity has been identified at positions -8010 and $-6540 \mathrm{nt}$ on the coding strand, and positions $-8524,-8010,-6340$ and $-4021 \mathrm{nt}$ on the non-coding strand of the human IL-10 gene. Furthermore, transcription factor binding sites have been identified in this promoter, including NF-אB, NK-IL6, Oct1, CREB, AP1, GM-CSF and TATA box motif $(18,19)$. In particular, within 
the IL-10 gene regulatory region, the presence of an HPV E2 recognition consensus site has been reported in the position from -2203 to $-2191 \mathrm{nt}$, which is an element regulated by E2 protein (18). These findings suggest that HPV proteins may play an important role in the molecular regulation of the IL-10 gene during cervical cancer development. HPV E2 protein is a sequence-specific DNA-binding protein that recognizes the target sequence $\mathrm{ACCN}_{6} \mathrm{GGT}$ present in the LCR of all HPV genomes (21). HPV E2 protein activates or represses the transcriptional activity of viral or cellular gene promoters depending on the position from the E2-binding sites to the TATA box. Thus, E2 plays a key role in viral DNA replication, transcription and genome maintenance, and is involved in cellular gene transactivation $(22,23)$. As regards E2, transactivation properties are modulated by interaction with several cellular factors that regulate the recruitment of transcription factor IID family members (23).

To elucidate the molecular mechanisms of human IL-10 gene expression in cervical cancer mediated by HPV E2 and to evaluate the potential transactivation ability of HPV E2, we investigated the effects of HPV E2 protein on the promoter activity of the human IL-10 gene in cervical cancer cell lines. HPV E2 protein was found to interact with the DNA recognition sequence located at positions -2203 to $-2191 \mathrm{nt}$ in the IL-10 promoter. The results suggest a novel molecular pathway by which HPV E2 protein may stimulate IL-10 gene expression. This finding suggests a possible mechanism by which HPV proteins regulate IL-10 gene expression during cervical cancer development, which may serve as a strategy for the regulation of immune response mediated by HPV.

\section{Materials and methods}

Cell lines and culture conditions. Human tumor cervical HPV-negative (C-33A) and HPV-positive (HeLa) cells were obtained from the American Type Culture Collection (ATCC). The cell lines were cultured in DMEM (Invitrogen, Carlsbad, CA, USA) supplemented with $10 \%$ fetal bovine serum (FBS), $10 \mu \mathrm{g} / \mathrm{ml}$ penicillin and $10 \mu \mathrm{g} / \mathrm{ml}$ streptomycin (Life Technologies, Carlsbad, CA, USA) and maintained at $37^{\circ} \mathrm{C}$ in $5 \% \mathrm{CO}_{2}$. C-33A cells $\left(1 \times 10^{6}\right)$ were transfected with different construct plasmids containing the IL-10 promoter, and were co-transfected with pCMV16E2 plasmid.

Cloning strategy and constructs. The human IL-10 gene regulatory region was determined by PCR-amplification from PBMC genomic DNA using forward (5'-TTTTCTAGAT ACCTCCCTTCCCTGAC-3') and reverse (5'-TTTCTCGAG ATCTCGAAGCATGTTAGGC-3') primers. The PCR conditions were $94^{\circ} \mathrm{C}$ for $5 \mathrm{~min}, 94^{\circ} \mathrm{C}$ for $1 \mathrm{~min}, 60^{\circ} \mathrm{C}$ for $1 \mathrm{~min}$ and $72^{\circ} \mathrm{C}$ for $1 \mathrm{~min}$ for 35 cycles, followed by $72^{\circ} \mathrm{C}$ for $5 \mathrm{~min}$. For the PCR amplification reaction, $1 \mu \mathrm{g}$ cDNA, $2.5 \mathrm{mM}$ dNTP, 30 pmol of each of the primers and 0.5 units Taq DNA polymerase (Invitrogen) were used in a $50-\mu 1$ volume reaction. A 2,675-bp DNA fragment was obtained and the nucleotide sequence was identical to that reported previously (18) (GenBank ${ }^{\mathrm{TM}} / \mathrm{EMBL}$ Data Bank; accession number, X78437). The amplified DNA fragment was cloned in pGEM-T vector (Promega, Madison WJ, USA) and was digested with $X b a \mathrm{I}-X h o \mathrm{I}$ to produce a DNA fragment containing a region
2,543 bp upstream and $132 \mathrm{bp}$ downstream of the transcription start site. This DNA fragment was cloned into luciferase reporter pGL2Basic vector (Promega) and different constructs were generated by the deletion of IL-10 promoter (Fig. 1). The pGIL10VB1 construct (from -2,534 to $+132 \mathrm{nt}$ ) was generated by the cloning of a 2,675-bp DNA fragment into the XbaI-XhoI sites, which contains the E2 regulatory element $\mathrm{ACCN}_{6} \mathrm{GGT}$ previously identified in the IL-10 promoter (18). The pGIL10VB2 construct includes a 1,493-bp DNA insert (from -1,362 to -132 nt) cloned in PstI-XhoI sites. The pGIL10VB3 construct contains a 1,253-bp DNA fragment (from -1,121 to $+132 \mathrm{nt}$ ) and was generated by cloning into the EcoRV-XhoI sites. Neither the pGIL10VB2 nor the pGIL10VB3 construct contains the HPV E2 recognition site. The integrity of the constructs was verified by restriction pattern analysis and DNA sequencing.

DNA transfection and luciferase reporter gene assay. C-33A cells were transiently transfected using LipofectaminePlus reagent (Invitrogen) according to the manufacturer's instructions. The transfection assays were performed with pGIL10VB1, pGIL10VB2 and pGIL10VB3 plasmids, which contain the IL-10 promoter upstream of the luciferase coding sequence. The co-transfection assays were carried out with pCMV16E2 plasmid (24), which contains a strong CMV promoter upstream of the HPV16 E2 gene cDNA. The pGL2Control, pGL2Basic and pC18SPE2 plasmids (24) were used as transfection controls. The transfection experiments were performed with $2 \mu \mathrm{g}$ of total DNA. Cells were incubated with Lipofectamine Plus reagent (Invitrogen) for $4 \mathrm{~h}$, rinsed and replenished with DMEM containing 10\% FBS. After a 48-h transfection, cells were washed with 1X PBS, harvested and lysed with $100 \mathrm{ml}$ cold lysis buffer $(20 \mathrm{mM}$ Tris- $\mathrm{HCl}, \mathrm{pH} 7.4,10 \mathrm{mM} \mathrm{NaCl}, 10 \mathrm{mM} \mathrm{KCl}, 3 \mathrm{mM} \mathrm{MgCl}$, $0.5 \%$ Triton X-100, 0.5\% NP-40). The cellular extracts were collected by centrifugation. Total proteins $(50 \mu \mathrm{g})$ were used to determine the luciferase activity. To normalize the assay, luciferase activity was measured using the luciferase reporter gene assay (Boehringer, Ingelheim, Germany) with Autocop I luminometer equipment according to the manufacturer's instructions. Luminescence was calculated to normalize the results with respect to pGL-2 control promoterless vector and the efficiency of transfection. Transfection experiments were repeated at least four times independently.

Electrophoresis mobility shift assay (EMSA). EMSA was performed as previously reported (25). In this assay, the HPV31 E2 protein was purified with the GST gene fusion system (Pharmacia, Biotech, USA) from pGEX31E2 plasmid donated by Laimiris AL (Northwestern University Medical School, Chicago, IL, USA). An oligonucleotide containing the $\mathrm{E} 2$ recognition site from the IL-10 promoter (5'-ATAACCACGTAGGGTTGC-3') was used as a probe and was end-radiolabeled with T4 DNA polynucleotide kinase using $30 \mu \mathrm{Ci}$ of $\left[\gamma^{32} \mathrm{P}\right]-\mathrm{dATP}$ and purified on a $1 \%$ agarose gel. HPV31 E2 protein $(5 \mu \mathrm{g})$ was incubated for $20 \mathrm{~min}$ at room temperature with the radiolabeled probe $\left(1-2 \times 10^{5} \mathrm{cpm}\right)$ in band shift buffer (10 mM Tris- $\mathrm{HCl} \mathrm{pH} 7.5,50 \mathrm{mM} \mathrm{NaCl}$, $1 \mathrm{mM}$ DTT, $1 \mathrm{mM}$ EDTA and 5\% glycerol) containing $1 \mu \mathrm{g}$ poly $\mathrm{dI}-\mathrm{dC}$ as a non-specific competitor. For competition 
experiments, increasing molar excesses of poly dI-dC were added. DNA-protein complexes were resolved at low-isotonic strength by non-denaturing polyacrylamide gel electrophoresis (PAGE) on a 6\% gel containing 0.5X TBE buffer $(0.089 \mathrm{M}$ Tris base, $0.089 \mathrm{M}$ boric acid, 0.02 M EDTA, pH 8.0). The gel was pre-electrophoresed for $30 \mathrm{~min}$ at $200 \mathrm{~V}$, then the samples were applied and electrophoresis was performed at the same voltage for $3 \mathrm{~h}$ in a cold room. The gel was dried and subjected to autoradiography at $-70^{\circ} \mathrm{C}$ with an intensifier screen.

RT-PCR analysis. C-33A cells were trasfected with 2 and $3 \mu \mathrm{g}$ of pCMV16E2 plasmid, which contains cDNA from HPV16 E2, and cells were harvested and processed for RNA isolation using TRIzol reagent (Invitrogen) according to the manufacturer's protocol. The mRNA was obtained using oligo $\mathrm{dT}_{15-18}$, and cDNA synthesis was performed by incubation with M-MLV reverse transcriptase (Invitrogen) at $37^{\circ} \mathrm{C}$ for $1 \mathrm{~h}$. IL-10 gene expression was measured by RT-PCR using sense (5'ATGCCCAAGCTGAGAACCCA-3') and antisense (5'-TCTCAAGGGGCTGGGTCAGCTATCCCA-3') primers under the following conditions: $94^{\circ} \mathrm{C}$ for $5 \mathrm{~min}, 94^{\circ} \mathrm{C}$ for $30 \mathrm{sec}$, $55^{\circ} \mathrm{C}$ for $1 \mathrm{~min}$ and $72^{\circ} \mathrm{C}$ for $1 \mathrm{~min}$ for 35 cycles, followed by $72^{\circ} \mathrm{C}$ for $5 \mathrm{~min}$. A 450-bp DNA fragment was obtained. U937 cells, human monocytes-macrophages stimulated with PMA $1 \mathrm{ng} / \mu \mathrm{l}$ for $48 \mathrm{~h}$, were used as a positive control for IL-10 gene expression. GAPDH was used as a control and PCR was performed with sense (5'-ACCACAGTCCATGCCATCAC-3') and antisense (5'-TCCACCACCCTGTTGCTGTA-3') primers PCR conditions were $94^{\circ} \mathrm{C}$ for $5 \mathrm{~min}, 94^{\circ} \mathrm{C}$ for $1 \mathrm{~min}, 58^{\circ} \mathrm{C}$ for $1 \mathrm{~min}$ and $72^{\circ} \mathrm{C}$ for $1 \mathrm{~min}$ for 35 cycles, followed by $72^{\circ} \mathrm{C}$ for 5 min. A 452-bp DNA fragment was obtained. For each PCR amplification, $1 \mu \mathrm{g}$ cDNA, $2.5 \mathrm{mM}$ dNTP, 30 pmol primers and 0.5 units Taq DNA polymerase (Invitrogen) were used in a $50-\mu 1$ volume reaction.

\section{Results}

During HPV infection, the complete elimination of the virus is the main goal; however this objective remains elusive, despite the fact that antiviral immune response is significantly increased in many instances. Previously, we demonstrated that HPV infection induces IL-10 expression in patients with cervical cancer (26). In addition, an HPV E2 recognition site in the position from $-2,203$ to $-2,191 \mathrm{nt}$ in the human IL-10 promoter has been reported (18). To understand the mechanism of IL-10 gene regulation by HPV16 E2 protein, the effect of HPV E2 viral protein on IL-10 promoter activity was analyzed using the luciferase reporter gene assay. For this purpose, the human IL-10 regulatory region was amplified by PCR and several construct plasmids that contain different fragments of the IL-10 promoter region were generated (Fig. 1). C-33A cells were transfected with the constructs containing the IL-10 regulatory region alone and were co-transfected with pCMV16E2 expression plasmid, which expresses HPV E2 protein (Fig. 2). A construct containing the IL-10 complete promoter (pGIL10VB1 plasmid from $-2,534$ to $+132 \mathrm{nt}$ ) and the HPV E2 recognition site was considered the reference point.

The data show that when the cells were transfected with IL-10 complete promoter, the reporter gene activity was

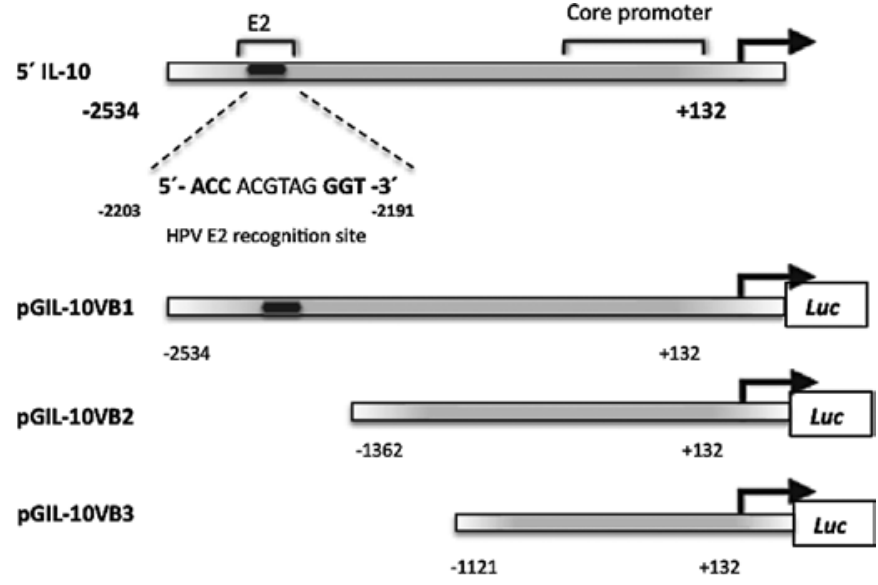

Figure 1. IL-10 promoter constructs. Representative diagram of the human IL-10 promoter region from $-2,534 \mathrm{bp}$ upstream to $132 \mathrm{bp}$ downstream of transcription start site (accession number, X78437). In the promoter region, the position of the HPV E2 recognition site is indicated. Various constructs (pGIL10VB1, pGIL10VB2 and pGIL10VB3) were generated in the pGL2Basic expression vector, which contains the luciferase reporter gene, by deletion of different sites in the IL-10 promoter region. The pGIL10VB1 plasmid contains the HPV E2 recognition site, while the pGIL10VB2 and pGI110VB3 plasmids lack of this sequence.

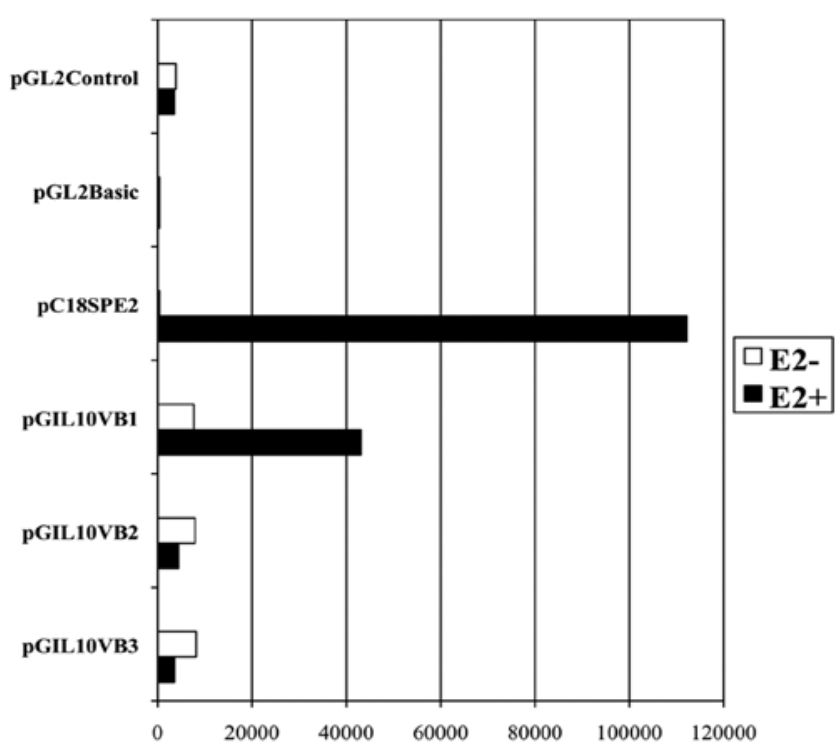

Luc activity in relative light units (RLU)

Figure 2. Funtional analysis of IL-10 promoter activity transactivated by HPV16 E2. Transcriptional activation of IL-10 promoter was induced by HPV16 E2 protein. C-33A cells were transiently transfected with the pGIL10VB1, pGIL10VB2 and pGIL10VB3 constructs and co-transfected with pCMV16E2 expression plasmids. After a 48-h co-transfection, Luc activity levels were measured. The pGL2Control, pGL2Basic and pC18SPE2 plasmids were used as transfection controls. White bars correspond to IL-10 promoter activity alone, while the grey and black bars indicate the IL-10 promoter activity induced by HPV16 E2 protein, respectively. Data are representative of three independent experiments.

detected as relative promoter activity (up to 7,500 RLU). This promoter activity was increased by 6-fold (up to 40,000 RLU) when the cells were co-transfected with pCMV16E2. When the cells were transfected with constructs that did not contain the HPV E2 recognition site (pGIL10VB2 plasmid from -1,362 


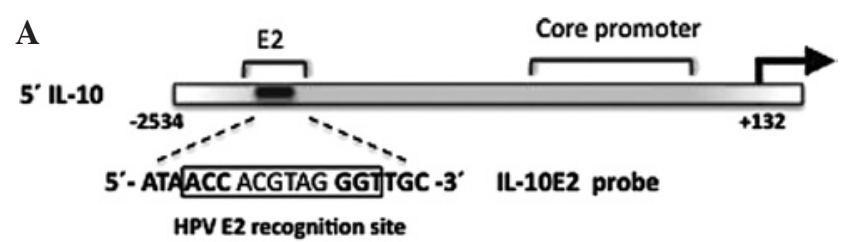

B

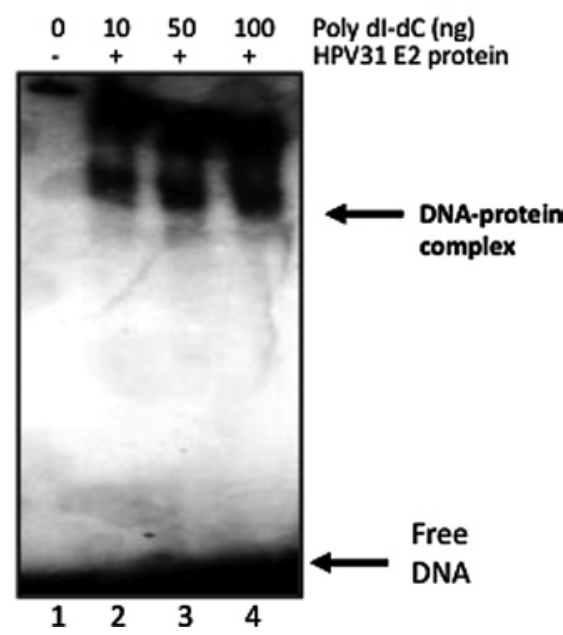

Figure 3. EMSA analysis of the IL-10 promoter. (A) IL-10 promoter exhibiting the oligonucleotide sequence corresponding with that of the IL10E2 probe, which contains the HPV E2 recognition site. (B) EMSA analysis of IL10E2. The oligonucleotide was radiolabeled with $\left[\gamma_{-}{ }^{32} \mathrm{P}\right]-\mathrm{dATP}$ and incubated with purified HPV31 E2 protein (lanes 2-4). The HPV31 E2 protein and the IL-10 probe were incubated with increasing amounts of poly dI-dC. The retarded DNA-protein complex and free-DNA are shown. Data are representative of three independent experiments.

to $+132 \mathrm{nt}$ and pGIL10VB3 plasmid from $-1,121$ to $+132 \mathrm{nt}$ ), the promoter activity was similar to that of the IL-10 complete promoter. However, when the co-transfection was carried out with pCMV16E2, the promoter activity was decreased by 2-fold (up to 3,500 RLU) compared to the promoter activity induced by pGIL10VB1. In parallel, a set of C-33A cells were transfected with the pGL2Control vector, which contains an SV40 promoter and enhancer sequences upstream of the luciferase gene as a control. Basal luciferase activity was observed. The pGL2Basic vector was used as a negative control lacking the eukaryotic promoter and enhancer sequences. The pC18SPE2 vector was also used as a positive control containing four HPV16 E2 regulatory elements and two Sp1 regulatory elements upstream of the luciferase gene (Fig. 2). Thus, the data demonstrate that with the use of the 5 '-distal end sequence from IL-10 promoter, which contains the HPV E2 recognition site, gene reporter activity was induced by the HPV E2 protein. These results support the notion that HPV E2 protein, which is involved in HPV gene expression, is also able to transactivate human IL-10 gene expression throughout the HPV E2 recognition site into the IL-10 promoter.

To confirm the effects of the HPV E2 protein on the transactivation mechanism of the IL-10 promoter and the importance of physical interaction with the HPV E2 recognition site, the E2-binding site of the IL-10 promoter was characterized. For this purpose, a synthetic DNA probe was designed containing the HPV E2 recognition sequences present in the IL-10 promoter, and the ability of HPV E2 protein to interact

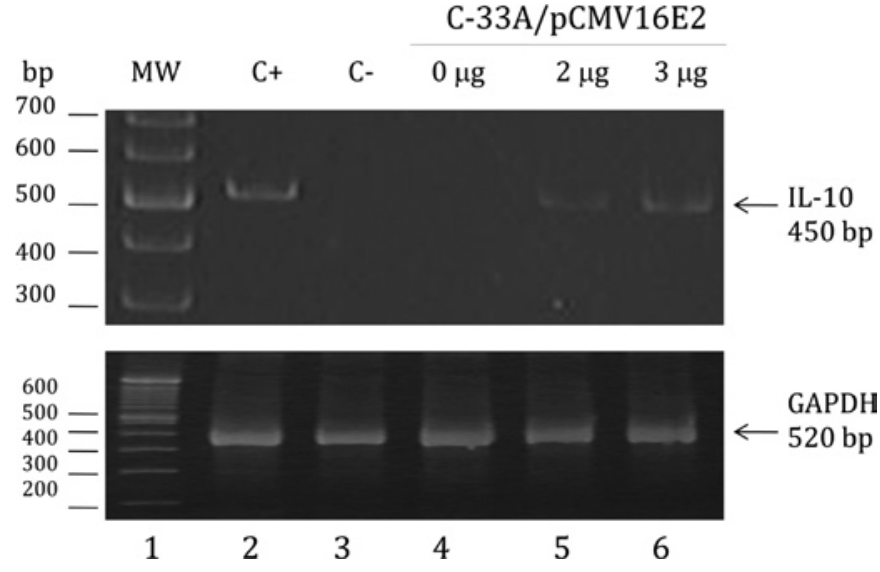

Figure 4. IL-10 gene expression in human tumor cervical cell lines. (A) RT-PCR analysis of IL-10 gene expression in HPV-negative tumor cervical cell lines (C-33A cells). U937 human monocyte-macrophage cells stimulated with PMA were used as a positive control for IL-10 gene expression. Samples were separated on $1 \%$ agarose gel. A 100-bp DNA ladder was used as a molecular weight marker. (B) Bands in the top panel were scanned using computer-assisted densitometry (Fluor-S-Multi-imager; Bio-Rad), and data were plotted as the ratio of IL-10/GAPDH mRNA. Assays were performed in triplicate and representative results are shown.

with the E2-binding site was determined using an EMSA assay. Fig. 3 shows the IL-10 promoter and an oligonucleotide sequence containing the E2-binding site (IL10E2 probe). A retarded DNA-protein complex was observed with the IL10E2 probe when it was incubated with HPV31 E2 purified protein (Fig. 3, lanes 2-4). To define the specificity of this retarded complex, a competition experiment was performed with increasing amounts $(1,10,50$ and $100 \mu \mathrm{g})$ of poly-dI-dC. The results showed that the retarded DNA-protein complex was not competed by the poly-dI-dC. Thus, the DNA-protein interactions suggest that HPV E2 protein is capable of binding to the IL-10 promoter, in particular with the HPV E2 recognition site, which may in part be responsible for the IL-10 transactivation effect induced by HPV E2 protein. The relevance of our findings is based on the fact that IL-10 gene expression mechanisms are crucial to understanding the role of IL-10 in the process of carcinogenesis.

To evaluate whether HPV16 E2 protein induces IL-10 gene expression, human IL-10 mRNA expression was analyzed by semiquantitative RT-PCR endpoint analysis. For this purpose, C-33A cells, which are HPV-negative, were transfected with an increased amount of pCMV16E2 plasmid, which expresses HPV16 E2 protein. IL-10 gene expression was detected in the C-33A cells transfected with the plasmids and compared to the expression in non-transfected C-33A cells (Fig. 4, lanes 4-6). U937 cells, human monocytes-macrophages stimulated with PMA, were used as a positive control for IL-10 gene expression. The data suggest that HPV16 E2 protein is capable of inducing human IL-10 gene expression.

Taking together the evidence of functional activity, interaction with the HPV E2 recognition site, formation of a specific DNA-protein complex and IL-10 gene expression by HPV16 E2 protein, the results suggest a mechanism of transactivation of the IL-10 promoter region mediated by an association of HPV E2 protein with the human IL-10 promoter, which is real and functional. 


\section{Discussion}

IL-10, which was first recognized for its ability to inhibit the activation and effector function of $\mathrm{T}$ cells, monocytes and macrophages, is a multifunctional cytokine with diverse effects on most hemopoietic cell types. The main function of IL-10 appears to be to limit and ultimately terminate the inflammatory response. Furthermore, IL-10 regulates the growth and/ or differentiation of B cells, NK cells, cytotoxic and helper $\mathrm{T}$ cells, mast cells, granulocytes, dendritic cells, keratinocytes and endothelial cells. IL-10 plays a key role in the differentiation and function of a newly identified type of $\mathrm{T}$ cell, the $\mathrm{T}$ regulatory cell, which may figure prominently in the control of immune responses and tolerance in vivo (27). Uniquely among hemopoietic cytokines, IL-10 has closely related homologues in several virus genomes, which points to its crucial role in regulating immune and inflammatory responses (28). In addition, during cancer development, IL-10 is expressed by the tumor cells themselves, possibly suppressing the antitumor response. In other cases, IL-10 is produced by activated cells involved in the host antitumor response; thus IL-10 may be an indicator of a potent inflammatory response rather than immunosuppression. In particular, it has been found that IL-10 is highly expressed locally in biopsies from patients with premalignant lesions and cervical cancer, and may induce a local immunosuppressive state $(5,26,29,30)$. Thus, elucidating the mechanisms of IL-10 gene expression during cervical cancer development may aid in the understanding of IL-10 function in the context of the antitumor immune response.

In the present study, we report the regulation of the human IL-10 promoter by HPV E2 protein expression in C-33A cells, which are human cervical cancer HPV-negative cells. The results indicate that HPV16 E2 protein induces IL-10 promoter activity in cervical cancer HPV-negative cells, which suggests that HPV16 E2 may induce the transactivation of the human IL-10 gene. In an expression vector containing the luciferase reporter gene, we generated three different plasmid constructs having or lacking the HPV E2 regulatory element of the IL-10 promoter (Fig. 1). We found that cells transfected with plasmid expressing HPV16 E2 and having the HPV E2 regulatory element (pGIL10VB1) induced the expression of luciferase activity, while the other two plasmids that lack this HPV E2 regulatory element (pGIL10VB2 and pGIL10VB3) did not induce luciferase gene expression. These data were confirmed using a positive control plasmid containing four HPV16 E2 regulatory element consensus motifs and two promoterless negative control plasmids (Fig. 2).

Our data are consistent with those of previous studies on E2 function. In these studies, HPV E2 protein was found to bind as a homodimer to a 12-bp palindromic DNA sequence, ACCN $_{6}$ GGT, present in the LCR of all HPV genomes (21). After binding, E2 protein up-regulates or represses transcription from the adjacent promoter depending on cell type and protein levels, and this regulation controls the expression of the HPV E6 and E7 oncogenes. We demonstrated that HPV16 E2 protein induces IL-10 promoter activity when the HPV E2 recognition site $\mathrm{ACCN}_{6} \mathrm{GGT}$ is present in the promoter. This finding suggests that HPV E2 protein would induce the IL-10 gene expression in vivo. However, additional experimental evidence is necessary to demonstrate this effect in vivo.
Regarding the molecular mechanisms behind the induction of IL-10 promoter activity by HPV E2 protein, we analyzed the DNA-protein physical interaction of HPV E2 protein with the HPV E2 recognition site in the IL-10 promoter (Fig. 3). Notably, DNA-protein interaction assays using purified HPV31 E2 showed the presence of retarded DNA-protein complex formation. Our results revealed that HPV E2 protein has the ability to physically bind with the promoter region of the IL-10 gene, and to induce promoter activity (Fig. 2). In addition, it is known that HPV E2 protein contains three domains: the amino-terminal domain, which mediates the transcription and replication properties of the protein, the carboxyl-terminal domain, which is responsible for homodimerization and binding to DNA, and the hinge region between these two domains. The carboxyl-terminal domain of HPV E2 protein is likely to be involved in both the induction of promoter activity and retarded DNA-protein complex formation. Further studies are required to confirm the function of the DNA-binding domain of HPV E2 protein within the IL-10 gene regulatory region; however, we propose that the effect of HPV E2 protein on the transactivation of the IL-10 gene regulatory region is mediated through the physical and functional interaction of HPV E2 protein with the IL-10 gene regulatory region.

HPV E2 protein regulates the transcription and replication of the HPV genome. Here, we demonstrated that E2 protein also transactivates IL-10 gene expression (Fig. 4). In the transcriptional control of IL-10 expression, several molecular complexes are involved which influence IL-10 gene expression throughout of dense clustering of potential regulatory response elements present in the IL-10 gene regulatory region (20). To determine whether HPV E2 induces IL-10 gene expression, we analyzed IL-10 mRNA expression by RT-PCR in HPV-negative tumor epithelial cells transfected with the HPV16 E2 gene. No expression of the IL-10 gene was found in cells not transfected with the HPV16 E2 gene, while human IL-10 mRNA expression was detected in cells transfected with the HPV16 E2 gene (Fig. 4). Thus, our results support the hypothesis that the IL-10 gene is regulated by HPV16 E2 protein activity. This effect may be explained by the properties of HPV E2 transactivation over the IL-10 promoter by association with the HPV E2 recognition site, which is in agreement with our previous results. Thus, our findings suggest that an event that occurs during HPV infection and may influence cervical cancer development consists of the induction of IL-10 gene expression by HPV E2 protein expression. This event represents an escape mechanism of antitumor immune repsonse, as IL-10 overexpression may generate an immunosuppression state in the tumor microenvironment $(6,26)$.

The IL-10 cytokine is a central component of immune response as it offers control over inflammatory and cellmediated immunological mechanisms (28). This is reflected in its apparent involvement in many immunological diseases, including autoimmune disorders, infection diseases and in particular malignancies. In addition, several reports have shown that IL-10 is a target for many viruses in their attempt to subvert the human immune system $(31,32)$. In particular, IL-10 expression has been demonstrated to be associated with HPV infection in cervical cancer cells (6). Additionally, it has been reported that IL-10 induces the transcription of the early promoter of human papillomavirus type 16 (HPV16) through 
the 5'-sequence of the upstream regulatory region (33). The present findings contribute to explaining part of the molecular pathway by which HPV influences IL-10 gene expression; moreover, since IL-10 induces HPV oncoprotein expression, this may represent a vicious circle. These findings may lead to an understanding of the strategies of immune escape induced by viruses, and the activation of the antitumor immune response.

In addition, we previously reported a clear trend of IL-10 mRNA expression in HPV-positive patients, proportional with the degree of severity of the lesions (6). This IL-10 expression pattern is notable because, in low-grade squamous intraepithelial lesions where high HPV E2 protein expression levels have been registered, IL-10 gene expression is not abundant, while in high-grade squamous intraepithelial lesions, the cancer cells frequently harbor HPV DNA, which is integrated within the cellular DNA and contains intact E6 and E7 open reading frames, indicating that either or both HPV E6 and E7 oncoproteins are involved in the processes of carcinogenesis.

We propose that the molecular mechanisms of IL-10 promoter gene activation may involve different pathways regulated by HPV proteins. The analysis of regulatory elements in the IL-10 promoter has allowed the identification of transcriptional factor binding sites in this region, which are also recognized by the biological activities of other HPV proteins, such as the E5, E6 and E7 oncoproteins. It has been reported that the transactivation properties of these HPV oncoproteins (33-38), including HPV11 E6, induces the expression of human IL-10 (27). The HPV16 E6 oncoprotein regulates c-fos and fibronectin gene expression through the cAMP response element (CRE) $(33,34)$, induces TGF- $\beta 1$ through the Sp1 regulatory element (17), activates tymidine kinase A mediated by the GC sequences and CAAT box (11), and transactivates the prothymosin $\alpha$ and c-myc promoters (35). In this respect, it has been reported that HPV16 E7 interacts with the TATA box through TATA binding protein (36), and that both the E6 and E7 oncoproteins induce the activation of the c-fos gene throughout the CRE element (33). The E5 protein from HPV11 and HPV16 actives the c-fos promoter through the NF1-binding element (37). In analyzing the IL-10 gene regulatory region, it is evident that these regulatory elements, which are regulated by HPV proteins, are present in the IL-10 regulatory region. Thus, we propose that IL-10 gene regulation in cervical cancer may be mediated by HPV proteins during the various phases of the viral transformation process, and that this may contribute to the development of a local immune-suppressive state due to the presence of the IL-10 cytokine.

Attempts to elucidate the causes of impaired antiviral immunity have pointed to a role for the immunomodulatory cytokine IL-10 in the ability of viruses to establish persistence. Induction of IL-10 production by the host during chronic infection appears to be one of the viral means of altering the class of the antiviral immune response, and induces generalized immune suppression (38). Recent studies by us and others strongly suggest that IL-10 is responsible for viral persistence $(6,10,27)$.

\section{Acknowledgements}

This study was carried out at the Instituto Nacional de Salud Pública de México, and received federal financial support from the Ministry of Health, as well as from the National Council of Science and Technology (CONACYT) with file no. 87916.

\section{References}

1. Zur Hausen H: Papillomaviruses and cancer: from basic studies to clinical application. Nat Rev Cancer 2: 342-350, 2002.

2. Walboomers JM, Jacobs MV, Manos MM, Bosch FX, Kummer JA, Shah KV, Snijders PJ, Peto J, Meijer CJ and Munoz N: Human papillomavirus is a necessary cause of invasive cervical cancer worldwide. J Pathol 189: 12-19, 1999.

3. Clerici M, Merola M, Ferrario E, Trwabattoni D, Villa ML, Stefanon B, Venzon DJ, Shearer GM, De Palo G and Clerici E: Cytokine production patterns in cervical intraepithelial neoplasia: association with human papillomavirus infection. J Natl Cancer Inst 89: 185-187, 1987.

4. Bais AG, Beckmann I, Lindemans J, Ewing PC, Meijer CJ, Snijders PJ and Helmerhorst TJ: A shift to a peripheral Th2-type cytokine pattern during the carcinogenesis of cervical cancer becomes manifest in CIN III lesions. J Clin Pathol 58: 1096-100, 2005.

5. El-Sherif AM, Seth R, Tighe PJ and Jenkins D: Quantitative analysis of IL-10 and IFN-gamma mRNA levels in normal cervix and human papillomavirus type 16 associated cervical precancer. J Pathol 195: 179-185, 2001.

6. Bermúdez-Morales VH, Burguete AI, Gutierrez ML, Alcocer-González JM and Madrid-Marina V: Correlation between IL-10 expression and human papillomavirus infection in cervical cancer. A mechanism for immune response escape. Cancer Invest 26: 1037-1043, 2008.

7. De Waal Malefyt R, Haanen J, Roncarolo MG, te Velde A, Figdor C, Johnson K, Kastelein R, Yssel H and de Vries JE: Interleukin 10 (IL-10) and viral IL-10 strongly reduce antigen-specific human $\mathrm{T}$ cell proliferation by diminishing the antigen-presenting capacity of monocytes via downregulation of class II major histocompatibility complex expression. J Exp Med 74: 915-924, 1991.

8. De Waal Malefyt R, Abrams J, Bennett B, Figdor CG and de Vries JE: Interleukin 10 (IL-10) inhibits cytokine synthesis by human monocytes: an autoregulatory role of IL-10 produced by monocytes. J Exp Med 174: 1209-1220, 1991.

9. Díaz-Benítez CE, Navarro-Fuentes KR, Flores-Sosa JA, et al: CD3zeta expression and $\mathrm{T}$ cell proliferation are inhibited by TGF-beta1 and IL-10 in cervical cancer patients. J Clin Immunol 29: 532-544, 2009.

10. Bhairavabhotla RK, Verm V, Tongaonkar H, Shastri S, Dinshaw K and Chiplunkar S: Role of IL-10 in immune suppression in cervical cancer. Indian J Biochem Biophys 44: 350-356, 2007.

11. Desaintes C, Hallez S, van Alphen P and Burny A: Transcriptional activation of several heterologous promoters by the E6 protein of human papillomavirus type 16. J Virol 66: 325-333, 1992.

12. Desaintes C and Demeret C: Control of papillomavirus DNA replication and transcription. Semin Cancer Biol 7: 339-347, 1996.

13. Hoffmann R, Hirt B, Bechtold V, Beard P and Raj K: Different modes of human papillomavirus DNA replication during maintenance. J Virol 80: 4431-4439, 2006.

14. Genther SM, Sterling S, Duensing S, Münger K, Sattler C and Lambert PF: Quantitative role of the human papillomavirus type 16 E5 gene during the productive stage of the viral life cycle. J Virol 77: 2832-2842, 2003.

15. Hartley KA and Alexander KA: Human TATA binding protein inhibits human papillomavirus type 11 DNA replication by antagonizing E1-E2 protein complex formation on the viral origin of replication. J Virol 76: 5014-5023, 2002.

16. Dey A, Atcha IA and Bagchi S: HPV16 E6 oncoprotein stimulates the transforming growth factor-beta 1 promoter in fibroblasts through a specific GC-rich sequence. Virology 228: 190-199, 1997.

17. Peralta-Zaragoza O, Bermúdez-Morales VH, GutiérrezXicotencatl L, Alcocer-González JM, Recillas-Targa F and Madrid-Marina V: E6 and E7 oncoprotein from human papillomavirus type 16 induce activation of human transforming growth factor beta-1 promoter throughout Sp1 regulatory element. Viral Immunol 19: 468-480, 2006.

18. Kube D, Platzer C, von Knethen A, Straub H, Bohlen H, Hafner $M$ and Tesch $H$ : Isolation of the human interleukin 10 promoter. Characterization of the promoter activity in Burkitt's lymphoma cell lines. Cytokine 7: 1-7, 1995. 
19. Eskdale J, Kube D, Tesch H and Gallager G: Mapping of the human IL-10 gene and further characterisation of the 5'-flanking sequence. Immunogenetics 46: 120-128, 1997.

20. Kube D, Rieth H, Eskdale J, Kremsner PG and Gallagher G: Structural characterization of the distal 5' flanking region of the human interleukin-10 gene. Genes Immun 2: 181-190, 2001.

21. Androphy EJ, Lowy DR and Schiller JT: Bovine papillomavirus E2 transactivating gene product binds to specific sites in papillomavirus DNA. Nature 325: 70-73, 1987.

22. Guido M, Zamorano R, Garrido-Guerrero E, Gariglio P and García-Carrancá A: Early promoters of genital and cutaneous human papillomaviruses are differentially regulated by the bovine papillomavirus type 1 E2 gene product. J Gen Virol 73 : 1395-1400, 1992.

23. Stenlund A and Botchan MR: The E2 trans-activator can act as a repressor by interfering with a cellular transcription factor. Genes Dev 4: 123-136, 1990.

24. Veress G, Szarka K, Dong XP, Gergely L and Pfister H: Functional significance of sequence variation in the E2 gene and the long control region of human papillomavirus type 16. J Gen Virol 80: 1035-1043, 1999.

25. Sambrook J, Fritsch EF and Maniatis T: Molecular Cloning Laboratory Manual. 2nd edition. Cold Spring Harbor Laboratory Press, pp89-99, 1989.

26. Alcocer-González JM, Berumen Jaime, Taméz-Guerra R, Bermúdez-Morales V, Peralta-Zaragoza O, Hernández-Pando R, Moreno J, Gariglio P and Madrid-Marina V: In vivo expression of immunosuppressive cytokines in human papillomavirus-transformed cervical cancer cells. Viral Immunol 19: 481-491, 2006.

27. Filippi CM and von Herrath MG: IL-10 and the resolution of infections. J Pathol 214: 224-230, 2008.

28. Moore WK, Malefyt WR, Coffman LR and O'Garra A: Interleukin-10 and the interleukin-10 receptor. Annu Rev Immunol 19: 683-765, 2001.

29. Azar KK, Tani M, Yasuda H, Sakai A, Inoue M and Sasagawa T: Increased secretion patterns of interleukin-10 and tumor necrosis factor-alpha in cervical squamous intraepithelial lesions. Hum Pathol 35: 1376-1384, 2004.
30. Bhairavabhotla RK, Verm V, Tongaonkar H, Shastri S, Dinshaw K and Chiplunkar S: Role of IL-10 in immune suppression in cervical cancer. Indian J Biochem Biophys 44: 350-356, 2007.

31. Burdin N, Péronne C, Banchereau J and Rousset F: Epstein-Barr virus Induces B lymphocytes to produce human interleukin-10. J Exp Med 177: 295-305, 1993.

32. Akridge RE, Oyafuso LKM and Reed SG: IL-10 is induced during HIV-1 infection and is capable of decreasing viral replication in human macrophages. J Immunol 153: 5782, 1994.

33. Arany A, Grattendick KG and Tyring SK: Interleukin-10 induces transcription of the early promoter of human papillomavirus type 16 (HPV16) through the 5'-segment of the upstream regulatory region (URR). Antiviral Res 55: 331-339, 2002.

34. Shino Y, Shirasawa H, Kinoshita T and Simizu B: Human papillomavirus type 16 E6 protein transcriptionally modulates fibronectin gene expression by induction of protein complex binding to the cyclic AMP response element. J Virol 71: 4310-4318, 1997

35. Kinoshita T, Shirasawa h, Shino Y, Moriya H, Desbarats L, Eilers M and Simizu B: Transactivation of prothymosin alpha and c-myc promoters by human papillomavirus type 16 E6 protein. Virology 232: 53-61, 1997.

36. Phillips $\mathrm{AC}$ and Vousden $\mathrm{KH}$ : Analysis if the interaction between human papillomaviris type 16 E7 and TATA-binding protein, TBP. J Gen Virol 78: 905-909, 1997.

37. Chen SL, Lin YK, Li LY, Tsao YP, Lo HY, Wang WB and Tsai TC: E5 proteins of human papillomavirus types 11 and 16 transactivate the $\mathrm{c}$-fos promoter through the NF1 binding element. J Virol 70: 8558-8563, 1996.

38. DeVoti JA, Steinberg BM, Rosenthal DW, Hatam L, Vambutas A, Abramson AL, Shikowitz MJ and Bonagura VR: Failure of gamma interferon but not interleukin-10 expression in response to human papillomavirus type 11 E6 protein in respiratory papillomatosis. Clin Diagn Lab Immunol 83: 538-547, 2004. 